\title{
The Impact of OnabotulinumtoxinA vs. Placebo on Efficacy Outcomes in Headache Day Responder and Nonresponder Patients with Chronic Migraine
}

\author{
Stephen D. Silberstein · Hans-Christoph Diener · David W. Dodick • \\ Aubrey Manack Adams · Ronald E. DeGryse · Richard B. Lipton
}

Received: July 27, 2020 / Accepted: September 14, 2020 / Published online: October 7, 2020

(C) The Author(s) 2020

\begin{abstract}
Introduction: The phase 3 PREEMPT trials demonstrated efficacy and tolerability of onabotulinumtoxinA for headache prevention in adults with chronic migraine. OnabotulinumtoxinA significantly reduced headache frequency from baseline vs. placebo at 24 weeks; however, this measure may not fully capture the benefits of treatment. We evaluated the impact of onabotulinumtoxinA on patient-reported outcomes according to headache responder status.
\end{abstract}

Digital Features To view digital features for this article go to https://doi.org/10.6084/m9.figshare.12951419.

S. D. Silberstein $(\bowtie)$

Thomas Jefferson University, Philadelphia, PA, USA

e-mail: stephen.silberstein@jefferson.edu

H.-C. Diener

Institute for Medical Informatics, Biometry and Epidemiology, University of Duisburg-Essen, Essen, Germany

D. W. Dodick

Mayo Clinic, Phoenix, AZ, USA

A. Manack Adams

Allergan, an AbbVie Company, Irvine, CA, USA

R. E. DeGryse

AbbVie, Irvine, CA, USA

R. B. Lipton

Albert Einstein College of Medicine, Bronx, NY, USA
Methods: A post hoc analysis pooled 24-week data from the placebo-controlled, randomized, double-blind treatment phases of the PREEMPT trials. Patients were stratified by randomized treatment (onabotulinumtoxinA vs. placebo) and headache day responder status (responder vs. nonresponder). Headache day responders had $\mathrm{a} \geq 50 \%$ headache day reduction from baseline measured at weeks 21-24. Outcomes evaluated were patient-reported reductions in moderate-to-severe headache days, Headache Impact Test, and Migraine-Specific Quality of Life Questionnaire. Missing values were estimated using a modified last-observation-carried-forward approach.

Results: In the pooled analysis population $(N=1384$; onabotulinumtoxinA, $n=688$; placebo, $n=696$ ), headache day responder rates were 308/688 (45\%) for onabotulinumtoxinAand 238/696 (34\%) for placebo-treated patients. At 24 weeks compared with baseline, onabotulinumtoxinA nonresponders showed significantly (all $P<0.01$ ) greater mean (standard error) reductions vs. placebo nonresponders in moderate-to-severe headache days (-3.5 [0.2] vs. - $2.4[0.2]$ ) and Headache Impact Test scores $(-2.3[0.3]$ vs. $-0.8[0.2])$, and greater mean improvements in Migraine-Specific Quality of Life Questionnaire domains (Restrictive, 8.8 [1.0] vs. 2.9 [0.8]; Preventive, 6.0 [1.0] vs. 1.8 [0.8]; Emotional, 8.5 [1.3] vs. 2.8 [1.1]). Moderate-to-severe headache day and headache impact differences between nonresponder 
groups were evident at week 4 and sustained through week 24.

Conclusions: Relative to placebo nonresponders, onabotulinumtoxinA nonresponders experienced significant reductions in moderateto-severe headache days and disability and improvement in quality of life, implying that the full benefits of onabotulinumtoxinA are not captured by headache day reduction.

Trial Registration: ClinicalTrials.gov identifiers, NCT00156910 (PREEMPT 1) and NCT00168428 (PREEMPT 2).

Keywords: Botulinum toxin type A; Chronic migraine; Headache; Quality of life

\section{Key Summary Points}

\section{Why carry out this study?}

In clinical trials of preventive treatments for chronic migraine (CM), patients have traditionally been classified as treatment responders or nonresponders by the binary threshold of at least a 50\% reduction in headache day frequency.

While this dichotomy is convenient for summarizing and communicating the benefits of treatment in trial populations, it does not fully reflect the benefits observed in clinical practice.

We hypothesized that patients treated with onabotulinumtoxinA but classified as headache day nonresponders may still experience reductions in moderate-tosevere headache days and improvements in patient-reported outcomes compared with placebo headache day nonresponders.

\section{What was learned from the study?}

OnabotulinumtoxinA treatment was associated with significantly greater improvements compared with placebo in days with moderate-to-severe headache, headache-related impact, and quality of life in both headache day responders and nonresponders.
These results support a treatment benefit for onabotulinumtoxin A in $\mathrm{CM}$ at 24 weeks that may not be fully captured by the observed reduction in headache days and is not confined to responder groups.

Thus, when evaluating treatment, practitioners and payers should consider relevant outcomes to determine clinically meaningful responses, as patients with $\mathrm{CM}$ who fail to achieve the traditional headache day response may still benefit from treatment.

\section{DIGITAL FEATURES}

This article is published with digital features to facilitate understanding of the article. To view digital features for this article go to https://doi. org/10.6084/m9.figshare.12951419.

\section{INTRODUCTION}

Chronic migraine $(\mathrm{CM})$ is a distinct neurological disease defined by the International Classification of Headache Disorders 3rd edition (ICHD-3) by at least 15 headache days per month, eight of which fulfill migraine criteria, not attributable to another disorder [1]. CM is estimated to affect 1 to $2 \%$ of the global population [2]. CM has a more debilitating disease profile than episodic migraine (characterized by less than 15 headache days per month), with patients experiencing a greater frequency of headache days, a greater frequency and severity of migraine-associated disability [3], and a greater prevalence of comorbid conditions (e.g., other chronic pain disorders, anxiety, depression) than episodic migraine $[4,5]$. Disabling migraine attacks prevent patients with $\mathrm{CM}$ from performing daily activities and significantly affect their quality of life, leading to substantial societal and familial burden $[4,6]$.

The identically designed phase 3, randomized REsearch Evaluating Migraine Prophylaxis Therapy (PREEMPT 1 and PREEMPT 2) pivotal 
trials evaluated the clinical efficacy and safety of onabotulinumtoxinA (Botox ${ }^{\circledR}$; Allergan plc, Dublin, Ireland) for preventive treatment in adult patients 18 to 65 years of age with $\mathrm{CM}$ $[7,8]$. Results from these trials demonstrated that compared with placebo, onabotulinumtoxinA treatment significantly reduced the frequency of headache days from baseline in patients with $\mathrm{CM}$ and yielded a significantly higher proportion of treatment responders, as measured by at least a 50\% reduction from baseline in headache days [9]. Results also showed that onabotulinumtoxinA treatment improved functioning and health-related quality of life compared with placebo $[7,8,10]$.

In clinical trials of preventive treatments for $\mathrm{CM}$, patients have traditionally been classified as treatment responders or nonresponders by the binary threshold of at least a 50\% reduction in headache day frequency $[11,12]$. While this dichotomy is convenient for summarizing and communicating the benefits of treatment in trial populations, it does not fully reflect the benefits observed in clinical practice. For example, using this approach, we would consider a patient with a $51 \%$ reduction in headache days a treatment success, while a patient with a $49 \%$ reduction would be considered a treatment failure. Similarly, a decrease in average attack duration from 20 to $4 \mathrm{~h}$ would not change the number of headache days; as a consequence, responder rates do not capture this benefit. There is a clinical impression that some "nonresponders" may receive benefits from onabotulinumtoxinA treatment that are not fully captured by the classic responder definition [13].

A previous analysis of pooled PREEMPT data found that headache day nonresponders who had received onabotulinumtoxinA treatment had significant reductions in severe headache days and headache severity compared with headache day nonresponders who had received placebo [14]. Therefore, to assess the potential benefits of onabotulinumtoxinA treatment not captured by at least a $50 \%$ reduction in headache days, we evaluated the impact of onabotulinumtoxinA treatment on patient-reported reductions in moderate-to-severe headache days, and improvements in patient-reported outcomes of headache impact and quality of life in adult patients with $\mathrm{CM}$ who were headache day responders and nonresponders. This approach aligns with International Headache Society (IHS) guidelines for controlled trials in migraine prevention, which encourage consideration of health-related quality of life and disability outcomes as endpoints [12]. We hypothesized that patients treated with onabotulinumtoxinA but classified as headache day nonresponders may still experience reductions in moderate-to-severe headache days and improvements in patient-reported outcomes compared with placebo headache day nonresponders.

\section{METHODS}

\section{Study Design}

The methods used in the PREEMPT 1 and 2 pivotal clinical trials have been reported previously $[7,8]$ and are briefly summarized here. This pooled, post hoc analysis used 24-week data from the phase 3 PREEMPT trials $[7,8]$, which were conducted from January 23, 2006 to August 11, 2008, at 122 sites across six different countries. Both trials included a 28-day baseline period, a 24-week double-blind, randomized treatment period, and a 32-week open-label phase. Patients were randomized $1: 1$ to receive intramuscular injections of onabotulinumtoxinA or placebo on day 0 and at week 12, followed by open-label treatment with onabotulinumtoxinA at weeks 24, 36, and 48 .

As described previously $[7,8]$, both trials discussed in this article were conducted in accordance with the Declaration of Helsinki Code of Federal Regulations and Good Clinical Practices and US requirements of public registration (NCT00156910 [PREEMPT 1] and NCT00168428 [PREEMPT 2]). Investigators at each investigational site obtained approval from an independent ethics committee or a local institutional review board prior to study initiation. Written informed consent was obtained from each randomized patient. 


\section{Participants}

Inclusion and exclusion criteria for the individual PREEMPT studies have been reported previously $[7,8]$. Briefly, eligible patients were men or women 18 to 65 years of age with a history of migraine meeting the diagnostic criteria listed in the 2004 International Classification of Headache Disorders, 2nd edition (ICHD2) Sect. 1, Migraine [1], with the exception of "complicated migraine." During the 28-day baseline period, patients were required to provide diary data on at least 20 days and to have had at least 15 headache days (defined as a calendar day consisting of 4 or more hours of continuous headache), of which at least 50\% were migraine or probable migraine days (referred to hereafter as migraine days), and to have had 4 or more distinct headache episodes each lasting at least $4 \mathrm{~h}$. Patients were excluded if they had used any headache prophylactic medication within 4 weeks prior to the study start at baseline, had previous exposure to any botulinum toxin serotype, or had a positive urine pregnancy test.

Patients in this pooled analysis were stratified by randomized treatment (onabotulinumtoxinA vs. placebo) and headache day responder status (responder vs. nonresponder). Headache day responders were defined as patients who achieved at least a 50\% reduction from baseline in headache day frequency for the 4 -week period ending with week 24; headache day nonresponders were defined as patients who achieved less than a 50\% reduction from baseline in headache day frequency for the 4 -week period ending with week 24. Due to high placebo response rates for efficacy and known adverse events (AEs) [9], for this analysis we compared between onabotulinumtoxinA nonresponders and placebo nonresponders instead of the entire placebo group.

\section{Study Assessments}

The clinical impact of treatment was evaluated by assessment of changes from baseline in the following 3 outcome measures: (1) patient-rated headache severity, based on a scale of $0=$ none to
3 = severe, as recorded in a voice-interactive daily telephone diary and summarized over 4-week intervals, ending with weeks 4, 8, 12, 16, 20 , and 24 ; (2) headache impact, based on patient responses on the 6-item Headache Impact Test (HIT-6) [15] at weeks 4, 8, 12, 16, 20, and 24; and (3) health-related quality of life, as determined by patient responses on the Migraine-Specific Quality of Life Questionnaire version 2.1 (MSQv2.1) [16, 17] at weeks 12 and 24. Note that while improvement from baseline involved decreased scores for HIT-6, it involved increased scores for MSQv2.1. AEs and treatment-related AEs (TRAEs) were summarized for each treatment group by headache day responder status.

\section{Statistical Analyses}

Results were summarized with descriptive statistics (mean, standard error [SE], frequency, or percentage). Differences between treatment groups were evaluated for HIT-6 and MSQv2.1 with the non-parametric Wilcoxon rank-sum test. For headache days, differences were evaluated by covariate analysis of variance, with baseline as covariate, using type III sum of squares via SAS statistical software. Differences in responder incidences were evaluated with Fisher's exact test. Missing values were estimated with a modified last-observation-carried-forward (mLOCF) approach, consisting of a patient's last observation, modified according to the average rate of change among all other patients, to roughly preserve the patient's rank position relative to the mean. Observed data, consisting of all patients with evaluable data at a given time point, are reported for classification of headache day responders for comparison purposes only. The post hoc analyses reported here were exploratory in nature, and were therefore performed without prespecified multiplicity adjustments. However, a highly conservative Bonferroni adjustment was used for the week 24 primary time point to modify the critical level from 0.05 to 0.005 to account for the five study assessments for each of the two responder subgroups (i.e., $0.05 / 10=0.005)$. Small $P$ values for other time points were considered supportive of significant results for the primary time point. 


\section{RESULTS}

\section{Headache Day Responders and Nonresponders}

The pooled analysis population contained a total of 1384 patients (onabotulinumtoxinA, $n=688$; placebo, $n=696$ ). Table 1 shows the headache day responder status at week 24 , as determined separately for the mLOCF and observed data analysis methods $[9,13]$. As both methods produced similar results, the mLOCF method was used for all subsequent analyses, since it allows for a larger number of patients to be analyzed. In the mLOCF analysis, for the onabotulinumtoxinA group, 308/688 (44.8\%) patients were headache day responders, and $380 / 688(55.2 \%)$ were headache day nonresponders; in the placebo group, 238/696 $(34.2 \%)$ were headache day responders, and $458 / 696$ (65.8\%) were headache day nonresponders. The baseline patient demographics and headache characteristics of headache day responders and nonresponders from each treatment arm were similar and are summarized in Table 2.

\section{Moderate-to-Severe Headache Day Response}

Reductions from baseline to week 24 in the numbers of moderate-to-severe headache days are shown for all four subgroups in Fig. 1. Reductions were significantly greater in
onabotulinumtoxinA-treated nonresponders compared with placebo nonresponders throughout the 24-week double-blind period. At week 24, the mean (standard error [SE]) reduction in moderate-to-severe headache days was - $3.5(0.2)$ days for onabotulinumtoxinAtreated nonresponders and $-2.4(0.2)$ days for placebo nonresponders $(P<0.001)$. Treatment differences between onabotulinumtoxinA-treated nonresponders and placebo nonresponders were evident at week 4 and sustained throughout the 24 weeks of double-blind treatment.

Both onabotulinumtoxinA and placebo headache day responders showed a decrease in moderate-to-severe headache days as early as week 4, and this decrease was sustained throughout 24 weeks of randomized treatment. No significant treatment differences were observed between onabotulinumtoxinA-treated responders and placebo-treated responders $(P>0.05)$ except at week 20. However, even though reductions in moderate-to-severe headache days in responders were similar between treatment groups, there was a notable and statistically significant difference in the percentage of responders favoring onabotulinumtoxinA (45\% vs. $34 \%$; $P<0.001$; Table 1 ).

\section{Headache Impact}

Reductions in headache impact from baseline to week 24, as measured by changes from baseline in HIT-6 total scores, are shown for all subgroups in Fig. 2. Reductions in headache impact

Table 1 Pooled analysis of PREEMPT trials: $50 \%$ headache day responders ${ }^{a}$ by $\mathrm{mLOCF}$ and observed data analyses at 24 weeks

\begin{tabular}{llllll}
\hline & \multicolumn{2}{l}{ OnabotulinumtoxinA } & & Placebo & \\
\cline { 2 - 3 } & $\begin{array}{l}\text { mLOCF } \\
(\boldsymbol{n}=\mathbf{6 8 8})\end{array}$ & $\begin{array}{l}\text { Observed } \\
(\boldsymbol{n}=\mathbf{5 3 9})\end{array}$ & & $\begin{array}{l}\text { mLOCF } \\
(\boldsymbol{n}=\mathbf{6 9 6})\end{array}$ & $\begin{array}{l}\text { Observed } \\
(\boldsymbol{n}=\mathbf{5 5 5})\end{array}$ \\
\hline Responder $^{\mathrm{a}}, n(\%)$ & $308(44.8)$ & $254(47.1)$ & & $238(34.2)$ & $195(35.1)$ \\
Nonresponder, $n(\%)$ & $380(55.2)$ & $285(52.9)$ & & $458(65.8)$ & $360(64.9)$ \\
\hline
\end{tabular}

$m L O C F$ modified last-observation-carried-forward

${ }^{a}$ Defined as at least a 50\% reduction in headache day frequency for the 4-week period ending with week 24 in either treatment group 
Table 2 Baseline patient demographics and headache characteristics of the pooled PREEMPT analysis population

\begin{tabular}{|c|c|c|c|c|}
\hline & \multicolumn{2}{|l|}{$50 \%$ Responders $^{\mathrm{a}}$} & \multicolumn{2}{|l|}{ Nonresponders } \\
\hline & $\begin{array}{l}\text { OnabotulinumtoxinA } \\
(n=308)\end{array}$ & $\begin{array}{l}\text { Placebo } \\
(n=238)\end{array}$ & $\begin{array}{l}\text { OnabotulinumtoxinA } \\
(n=380)\end{array}$ & $\begin{array}{l}\text { Placebo } \\
(n=458)\end{array}$ \\
\hline Age, mean (SD), years & $40.8(10.0)$ & $40.4(10.9)$ & $41.4(10.8)$ & $42.1(10.5)$ \\
\hline Female, $n(\%)$ & $277(89.9)$ & $203(85.3)$ & $326(85.8)$ & $390(85.2)$ \\
\hline \multicolumn{5}{|l|}{ Race, $n(\%)$} \\
\hline White & $277(89.9)$ & $212(89.1)$ & $340(89.5)$ & $418(91.3)$ \\
\hline Black & $14(4.5)$ & $16(6.7)$ & $20(5.3)$ & $24(5.2)$ \\
\hline Asian & $2(0.6)$ & $1(0.4)$ & $2(0.5)$ & $2(0.4)$ \\
\hline Hispanic & $12(3.9)$ & $6(2.5)$ & $15(3.9)$ & $13(2.8)$ \\
\hline Other & $3(1.0)$ & $3(1.3)$ & $3(0.8)$ & $1(0.2)$ \\
\hline $\begin{array}{l}\text { Age of onset of chronic migraine, } \\
\text { mean (SD), years }\end{array}$ & $21.5(10.8)$ & $21.6(11.7)$ & $20.9(11.2)$ & $22.1(12.1)$ \\
\hline Headache days, mean (SD) & $19.2(3.3)$ & $18.9(3.1)$ & $20.5(3.9)$ & $20.3(3.9)$ \\
\hline HIT-6 total score, mean (SE) & $65.3(0.2)$ & $65.4(0.3)$ & $65.7(0.2)$ & $65.4(0.2)$ \\
\hline \multicolumn{5}{|l|}{ MSQv2.1 domain scores, mean (SE) } \\
\hline Role Function-Restrictive & $59.6(0.9)$ & $60.0(1.1)$ & $63.0(0.9)$ & $62.0(0.8)$ \\
\hline Role Function-Preventive & $43.4(1.2)$ & $42.2(1.1)$ & $44.5(1.4)$ & $44.8(1.0)$ \\
\hline Emotional Function & $56.7(1.4)$ & $58.5(1.6)$ & $59.0(1.2)$ & $57.0(1.2)$ \\
\hline
\end{tabular}

HIT-6 6-item Headache Impact Test, MSQv2.1 Migraine-Specific Quality of Life Questionnaire version 2.1, SD standard deviation, $S E$ standard error

${ }^{a}$ Defined as at least a $50 \%$ reduction in headache day frequency for the 4-week period ending with week 24 in either treatment group

were significantly greater in onabotulinumtoxinA-treated nonresponders compared with placebo nonresponders throughout the 24-week double-blind period. The mean (SE) change in HIT-6 total score at 24 weeks was - $2.3(0.3)$ for onabotulinumtoxinA-treated nonresponders vs.

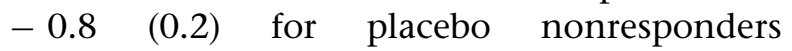
$(P<0.001)$. HIT-6 treatment differences between onabotulinumtoxinA-treated nonresponders and placebo nonresponders were evident at week 4 and sustained throughout the 24 weeks of double-blind treatment $(P<0.001)$.

OnabotulinumtoxinA treatment was also associated with significantly greater reductions in headache impact from baseline vs. placebo among headache day responders. At 24 weeks, the mean (SE) change from baseline in HIT-6 total score for onabotulinumtoxinA-treated responders was $-7.9(0.5)$ vs. $-5.5(0.5)$ for placebo responders $(P<0.001)$.

\section{Migraine-Specific Quality of Life Version 2.1}

Improvements in quality of life from baseline to week 24, as measured by mean (SE) changes from baseline in MSQv2.1 scores, are shown in Fig. 3. OnabotulinumtoxinA-treated nonresponders showed significantly greater mean (SE) improvements in quality of life at week 24 compared with placebo nonresponders. Mean (SE) improvements from baseline at week 24 


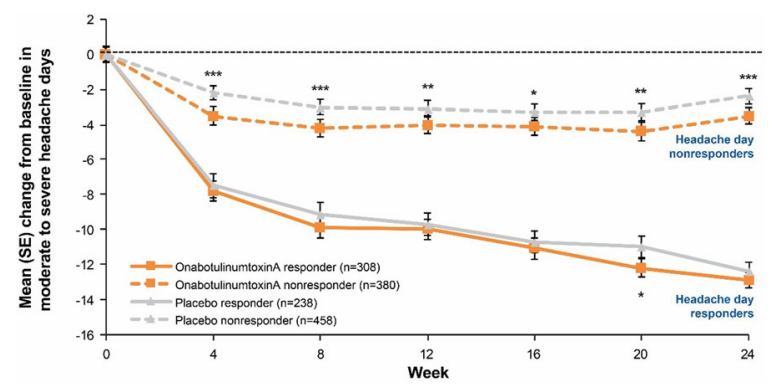

Fig. 1 Mean (SE) change from baseline in moderate-tosevere headache days. ${ }^{*} P<0.05 ; \quad{ }^{* *} P<0.01$; ${ }^{* * *} P<0.001 ; P$ values for between-treatment comparisons (e.g., placebo responder vs. onabotulinumtoxinA-treated responder). $P<0.001$ for all within-treatment comparisons (responder vs. nonresponder). $S E$ standard error

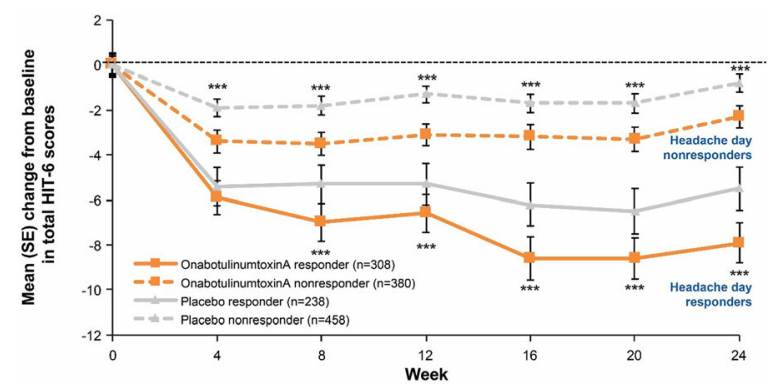

Fig. 2 Mean (SE) change from baseline in total HIT-6 scores. ${ }^{*} P<0.05 ;{ }^{* *} P<0.01 ;{ }^{* * *} P<0.001 ; P$ values for between-treatment comparisons (e.g., placebo responder vs. onabotulinumtoxinA-treated responder). $P<0.001$ for all within-treatment comparisons (responder vs. nonresponder). HIT-6 6-item Headache Impact Test, SE standard error

were $8.8 \quad(1.0) \quad$ vs. $2.9 \quad(0.8)$, respectively $(P<0.001)$, in Role Function-Restrictive domain score; $6.0(1.0)$ vs. $1.8(0.8)$, respectively $(P=0.003), \quad$ in Role Function-Preventive domain score; and 8.5 (1.3) vs. 2.8 (1.1), respectively $(P<0.001)$, in Emotional Function domain score. A sustained difference between onabotulinumtoxinA-treated nonresponders and placebo nonresponders was evident for all MSQv2.1 domain scores at 12 and 24 weeks $(P<0.05)$.

OnabotulinumtoxinA-treated responders showed significantly greater mean (SE) improvements in quality of life vs. placebo responders at week 24 . The mean improvements from baseline at week 24 were 26.2 (1.4) vs. 19.3 (1.6), respectively ( $P<0.001)$, in Role FunctionRestrictive domain score; 21.1 (1.3) vs. 15.0 (1.5), respectively $(P=0.001)$, in Role FunctionPreventive domain score; and 28.7 (1.6) vs. 21.9 (1.8), respectively $(P=0.006)$, in Emotional Function domain score.

\section{Adverse Events}

The incidence and severity of AEs and TRAEs, stratified by headache day responder status, are summarized in Table 3. OnabotulinumtoxinAtreated responders appeared to have a lower incidence of discontinuations due to AEs and similar rates of AEs, TRAEs, and serious AEs compared with onabotulinumtoxinA-treated nonresponders. Placebo responders appeared to have a higher incidence of TRAEs and no difference in AEs, serious AEs, and discontinuations due to AEs compared with placebo nonresponders.

\section{DISCUSSION}

This pooled analysis of data from the PREEMPT clinical trials was conducted to determine the impact of onabotulinumtoxinA treatment on patient-reported outcomes in adults with $\mathrm{CM}$ who were headache day responders and nonresponders. Outcomes examined were mean changes from baseline in moderate-to-severe headache day response, HIT- 6 total scores, and health-related quality of life based on MSQv2.1 domain scores. The results provide evidence that, compared with placebo, onabotulinumtoxinA provided significant treatment-related benefits in severity, functional impact, and quality of life as reported by patients, even in those who did not achieve 50\% headache day responder status. These findings indicate that measurable and statistically significant treatment benefits occurred in patients treated with onabotulinumtoxinA who were considered "nonresponders" by the traditional response threshold. This suggests that clinicians and patients must make more nuanced decisions about continuing or discontinuing migraine 
(a) Role Function - Restrictive

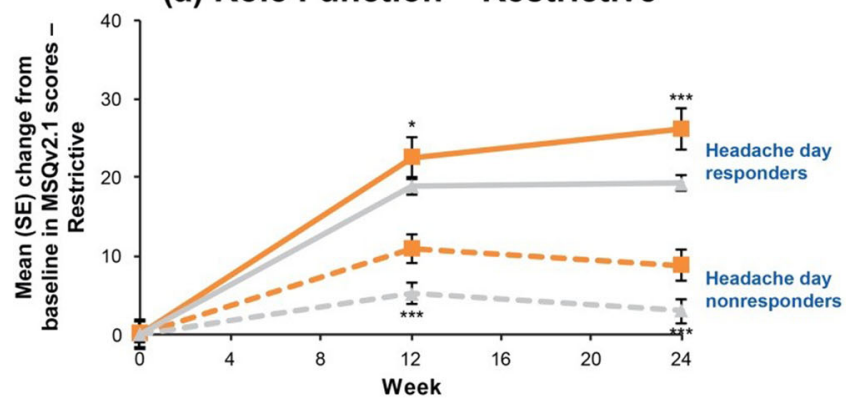

(b) Role Function - Preventive

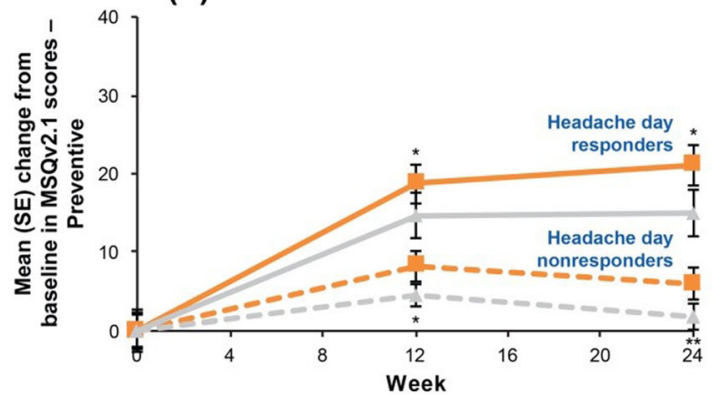

(c) Emotional Function

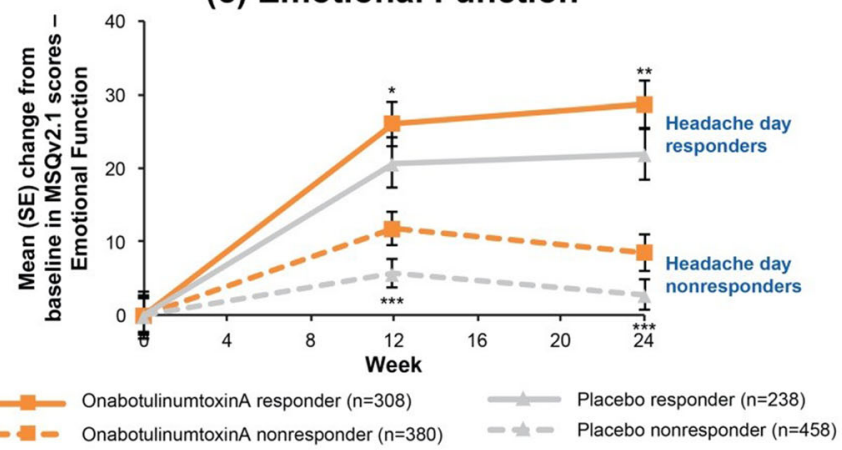

Fig. 3 Mean (SE) change from baseline in MSQv2.1 domain scores: a Role Function-Restrictive, b Role Function-Preventive, and c Emotional Function. ${ }^{*} P<0.05$; ${ }^{* *} P<0.01 ;{ }^{* * *} P<0.001 ; P$ values for between-treatment comparisons (e.g., placebo responder vs. onabotulinumtoxinA-treated responder). MSQv2.1 Migraine-Specific Quality of Life Questionnaire version 2.1, $S E$ standard error

Table 3 Adverse events (safety population)

\begin{tabular}{|c|c|c|c|c|}
\hline \multirow[t]{2}{*}{ AE category, $n(\%)$} & \multicolumn{2}{|l|}{ Responders $^{\mathrm{a}}$} & \multicolumn{2}{|l|}{ Nonresponders } \\
\hline & $\begin{array}{l}\text { Onabotulinumtoxin } A \\
(n=308)\end{array}$ & $\begin{array}{l}\text { Placebo } \\
(n=238)\end{array}$ & $\begin{array}{l}\text { OnabotulinumtoxinA } \\
(n=379)\end{array}$ & $\begin{array}{l}\text { Placebo } \\
(n=454)\end{array}$ \\
\hline Any AE & $188(61.0)$ & $126(52.9)$ & $241(63.6)$ & $232(51.1)$ \\
\hline Any TRAE & $91(29.5)$ & $34(14.3)$ & $111(29.3)$ & $54(11.9)$ \\
\hline Serious AEs & $14(4.5)$ & $7(2.9)$ & $19(5.0)$ & $9(2.0)$ \\
\hline Serious TRAEs & 0 & 0 & $1(0.3)$ & 0 \\
\hline Discontinuations due to AEs & $7(2.3)$ & $3(1.3)$ & $19(5.0)$ & $5(1.1)$ \\
\hline Deaths due to AEs & 0 & 0 & 0 & 0 \\
\hline
\end{tabular}

$A E$ adverse event, TRAE treatment-related adverse event

${ }^{a}$ Defined as at least a $50 \%$ reduction in headache day frequency for the 4-week period ending with week 24 in either treatment group 
preventive treatments that are based entirely on achievement of at least a 50\% reduction from baseline in headache days.

In this analysis, onabotulinumtoxinAtreated nonresponders showed a significantly greater reduction from baseline in the number of moderate-to-severe headache days and significantly greater reductions from baseline in HIT-6 total scores compared with placebo nonresponders. These reductions were observed starting at week 4 and were sustained throughout week 24. OnabotulinumtoxinA-treated nonresponders also showed significantly greater improvements in MSQv2.1 domain scores compared with placebo nonresponders at weeks 12 and 24.

OnabotulinumtoxinA-treated responders showed significantly greater reductions in HIT-6 total scores compared with placebo responders starting at week 8 that were sustained throughout week 24. OnabotulinumtoxinAtreated responders also showed significantly greater improvements in MSQv2.1 domain scores compared with placebo responders at weeks 12 and 24. Changes from baseline in moderate-to-severe headache days were similar for both onabotulinumtoxinA-treated responders and placebo responders. Interestingly, patient-reported moderate-to-severe headache severity was the only outcome measure in which a consistent treatment effect was not observed for both headache day responders and nonresponders. While onabotulinumtoxinAtreated nonresponders showed a greater reduction in moderate-to-severe headache days compared with patients randomized to placebo, this differential effect was not observed for responders. This could represent a possible ceiling effect, could be due to the closeness of the two outcomes (headache days and moderate-to-severe headache days), or the outcome measure, which uses a definition of pain that is at least moderate severity at any point, may not be sensitive enough to enable observation of differences between groups because it does not account for the total duration of moderate or severe pain. Within each treatment group, rates of AEs, TRAEs, and serious AEs did not differ between responders and nonresponders. OnabotulinumtoxinA-treated nonresponders had the highest incidence of discontinuations due to AEs (5.0\%) among the four subgroups.

Previous analyses of the pooled PREEMPT population showed a significant treatment effect at 24 weeks on HIT-6 total scores, frequency of headache days, and moderate-tosevere headache days [9]. The proportion of patients achieving at least a 50\% reduction from baseline in monthly headache days was also reported in the overall PREEMPT population, and is a widely used outcome measure to quantify the efficacy of a preventive treatment [9]. The current analysis shows that even patients who fail to meet "responder" status with respect to a reduction in headache days experience some quantifiable treatment benefit from onabotulinumtoxinA. These findings underscore the importance of preventive treatment with onabotulinumtoxinA for patients with $\mathrm{CM}$, as significant benefits are achieved early and sustained over time, even in patients who fail to achieve the traditional response of at least a 50\% reduction from baseline in headache days. Using the PREEMPT injection protocol for preventive treatment may also benefit patients with other chronic, difficult-to-treat headache disorders that are refractory to other treatments [18].

$\mathrm{CM}$ is a complex disease whose burden cannot be fully captured by a count of headache days; therefore, treatment decisions should not be based solely on that outcome. To this end, the European Headache Federation guidelines recommend continued use of onabotulinumtoxinA for patients with a headache day reduction of $\geq 30 \%$ in addition to consideration of headache intensity, disability, and patient preferences as well as continuing treatment for at least 2 to 3 treatment cycles before labeling a patient as nonresponsive [19]. Consistent with these guidelines, a quarter of Italian headache physicians surveyed believed that patients achieving $\mathrm{a} \geq 30 \%$ reduction in headache days were considered responders (instead of $\geq 50 \%$ reduction), and $40 \%$ of these clinicians believed that more than 4 treatment cycles were required before classifying a patient as a nonresponder [20]. Also supporting this guidance, a real-world study demonstrated that patients who do not achieve a 50\% reduction in headache days by 
the third onabotulinumtoxinA treatment cycle still exhibit improvements in disability and headache-related impact [21]. However, the outcomes measured may also impact the perception of treatment response, as a prospective study of patients with CM conducted in Spain showed that migraine-associated disability was more closely related to headache pain intensity than to headache frequency [22]. These validated patient-reported outcome measures provide meaningful information to guide treatment decisions.

These findings also support the value of assessing nontraditional efficacy measures in clinical trials, as such assessments can help to elucidate meaningful benefits of treatment and they align with the IHS recommendations [12]. In a clinical trial that evaluated the efficacy and safety of the calcitonin gene-related peptide receptor monoclonal antibody erenumab for the treatment of patients with episodic migraine (Study to Evaluate the Efficacy and Safety of Erenumab [STRIVE; NCT02456740]), results on nonstandard efficacy measures, including the Migraine Disability Assessment Questionnaire, HIT-6, and MSQv2.1, demonstrated the significant benefits of preventive treatment vs. placebo (all patients) [23]. A post hoc responder analysis of the STRIVE data used a responder definition similar to that used in the current analysis (at least a 50\% reduction in monthly migraine days instead of headache days) [24]. The authors showed that responders to preventive treatment achieved greater improvements compared with nonresponders, as measured by the Migraine Physical Function Impact Diary domain scores for everyday activity and physical impact. Although improvements from baseline were reported on outcome measures in nonresponders, no comparisons with placebo nonresponders were reported, as was done in the PREEMPT analyses [24].

Limitations of the PREEMPT1 and PREEMPT2 studies and pooled analysis of both PREEMPT studies have been discussed in previous publications [7-9]. These include the lack of an active comparator (no approved comparator was available at the time of the studies) and the relatively high placebo response rates, and these limitations also apply to the current analysis.
For this responder subgroup analysis, it may be argued that this exploratory post hoc analysis may not have the reliability and statistical power to make appropriate inferences. However, although these findings are supportive of the primary analysis between treatment arms, we believe these subgroups have never been analyzed before and, therefore, they have important clinical relevance on treatment decisions/modifications beyond considering only headache days.

\section{CONCLUSIONS}

OnabotulinumtoxinA treatment was associated with significantly greater improvements compared with placebo in days with moderate-tosevere headache, headache-related impact, and quality of life in both headache day responders and nonresponders, as typically defined by an arbitrary and binary cutoff of at least a 50\% reduction in headache days [11]. These results support a treatment benefit for onabotulinumtoxinA in $\mathrm{CM}$ at 24 weeks that may not be fully captured by the observed reduction in headache days and is not confined to responder groups. Thus, when evaluating treatment, practitioners and payers should consider relevant outcomes to determine clinically meaningful responses. As the current data show, patients with $\mathrm{CM}$ who fail to achieve the traditional headache day response may still benefit from treatment.

\section{ACKNOWLEDGEMENTS}

Funding. Sponsorship for this study and the journal's Rapid Service Fee were funded by Allergan (prior to its acquisition by AbbVie).

Authorship. All named authors meet the International Committee of Medical Journal Editors (ICMJE) criteria for authorship for this article, take responsibility for the integrity of the work as a whole, and have given their approval for this version to be published. 
Medical Writing, Editorial, and Other Assistance. Writing and editorial assistance was provided to the authors by Sean ShefflerCollins, PhD, at Peloton Advantage, LLC, an OPEN Health company, Parsippany, NJ, USA, and was funded by AbbVie. The opinions expressed in this article are those of the authors. The authors received no honorarium/fee or other form of financial support related to the development of this article.

Prior Presentation. Some of the data included in this manuscript were previously presented in poster form at the 13th European Headache Federation (EHF) Congress, May 30-June 1, 2019, Athens, Greece; the 5th Congress of the European Academy of Neurology (EAN), June 29-July 2, 2019, Oslo, Norway; the 61st Annual Scientific Meeting of the American Headache Society (AHS), July 11-14, 2019, Philadelphia, PA, USA; the Diamond Headache Clinic Research \& Educational Foundation's Headache (DHCREF) Update 2019, July 25-28, 2019, Lake Buena Vista, FL, USA; and the 19th Congress of the International Headache Society (IHC 2019), September 5-8, 2019, Dublin, Ireland.

Disclosure. Stephen D. Silberstein, MD: Consultant and/or advisory panel member for and has received honoraria from Alder Biopharmaceuticals, AbbVie, Amgen, Avanir, eNeura, ElectroCore Medical, Labrys Biologics, Medscape, Medtronic, Neuralieve, NINDS, Pfizer, and Teva. His employer receives research support from AbbVie, Amgen, Cumberland Pharmaceuticals, ElectroCore Medical, Labrys Biologics, Eli Lilly, Mars, and Troy Healthcare. Hans-Christoph Diener, MD, PhD: Received honoraria for participation in clinical trials, contribution to advisory boards, or oral presentations in the last 3 years from: Alder, AbbVie, Amgen, Bristol-Myers Squibb, Electrocore, Ipsen Pharma, Eli Lilly, Medtronic, MSD, Novartis, Pfizer, Teva, and Weber \& Weber. Financial support for research projects was provided by AbbVie and Electrocore. HCD serves on the editorial boards of Cephalalgia and Lancet Neurology. HCD co-chairs the Clinical Guidelines Committee of the German Society of
Neurology and is a member of the Clinical Trials Committee of the International Headache Society. David W. Dodick, MD: Reports the following conflicts within the past 12 months: Consulting: AEON, Amgen, Clexio, Cerecin, AbbVie, Alder, Biohaven, Linpharma, Lundbeck, Promius, Eli Lilly, eNeura, Novartis, Impel, Theranica, WL Gore, Nocira, XoC, Zosano, Upjohn (Division of Pfizer), Pieris, Revance, Equinox. Honoraria: CME Outfitters, Curry Rockefeller Group, DeepBench, Global Access Meetings, KLJ Associates, Majallin LLC, Medlogix Communications, Miller Medical Communications, Southern Headache Society (MAHEC), WebMD Health/Medscape, Wolters Kluwer, Oxford University Press, Cambridge University Press. Research Support: Department of Defense, National Institutes of Health, Henry Jackson Foundation, Sperling Foundation, American Migraine Foundation, Patient Centered Outcomes Research Institute (PCORI). Stock Options/Shareholder/Patents/Board of Directors: Aural Analytics (options), ExSano (options), Palion (options), Healint (options), Theranica (options), Second Opinion/Mobile Health (options), Epien (options/board), Nocira (options), Ontologics (options/board), KingDevick Technologies (options/board), Precon Health (options/board). Patent 17189376.11466:vTitle: Botulinum Toxin Dosage Regimen for Chronic Migraine Prophylaxis. Aubrey Manack Adams, PhD and Ronald E. DeGryse, MS, MA: Employees of AbbVie and may hold AbbVie stock. Richard B. Lipton, MD: Serves as consultant or advisory board member or has received honoraria from American Academy of Neurology, Alder, AbbVie, American Headache Society, Amgen, Biohaven, Biovision, Boston Scientific, Dr. Reddy's, Electrocore, Eli Lilly, eNeura Therapeutics, GlaxoSmithKline, Merck, Pernix, Pfizer, Teva, Trigemina, Vector, and Vedanta. Holds stock options in eNeura and Biohaven.

Compliance with Ethics Guidelines. Both trials discussed in this article were conducted in accordance with the Declaration of Helsinki Code of Federal Regulations and Good Clinical Practices and US requirements of public registration (NCT00156910 [PREEMPT 1] and 
NCT00168428 [PREEMPT 2]). Investigators at each investigational site obtained approval from an independent ethics committee or a local institutional review board prior to study initiation. Written informed consent was obtained from each randomized patient.

Data Availability. Data reported in this manuscript are available within the article and/ or its supplementary materials. AbbVie will share de-identified patient-level data and/or study-level data, including protocols and clinical study reports, for phase 2-4 trials completed after 2008 that are registered on ClinicalTrials.gov or EudraCT. The indication studied in the trial must have regulatory approval in the United States and/or the European Union and the primary manuscript from the trial must be published prior to data sharing. To request access to the data, the researcher must sign a data use agreement. All shared data are to be used for non-commercial purposes only. More information can be found on https://www. allerganclinicaltrials.com/PatientDataRequest. htm.

Open Access. This article is licensed under a Creative Commons Attribution-NonCommercial 4.0 International License, which permits any noncommercial use, sharing, adaptation, distribution and reproduction in any medium or format, as long as you give appropriate credit to the original author(s) and the source, provide a link to the Creative Commons licence, and indicate if changes were made. The images or other third party material in this article are included in the article's Creative Commons licence, unless indicated otherwise in a credit line to the material. If material is not included in the article's Creative Commons licence and your intended use is not permitted by statutory regulation or exceeds the permitted use, you will need to obtain permission directly from the copyright holder. To view a copy of this licence, visit http://creativecommons.org/ licenses/by-nc/4.0/.

\section{REFERENCES}

1. Headache Classification Committee of the International Headache Society. The International Classification of Headache Disorders, $3^{\text {rd }}$ edition. Cephalalgia. 2018;38:1-211.

2. Natoli JL, Manack A, Dean B, et al. Global prevalence of chronic migraine: a systematic review. Cephalalgia. 2010;30:599-609.

3. Lipton RB, Manack Adams A, Buse DC, Fanning KM, Reed ML. A Comparison of the chronic migraine epidemiology and outcomes (CaMEO) study and American migraine prevalence and prevention (AMPP) Study: demographics and headache-related disability. Headache. 2016;56:1280-9.

4. Blumenfeld AM, Varon SF, Wilcox TK, et al. Disability, HRQoL and resource use among chronic and episodic migraineurs: results from the international burden of migraine study (IBMS). Cephalalgia. 2011;31:301-15.

5. Buse DC, Manack A, Serrano D, Turkel C, Lipton RB. Sociodemographic and comorbidity profiles of chronic migraine and episodic migraine sufferers. J Neurol Neurosurg Psychiatry. 2010;81:428-32.

6. Lanteri-Minet M, Duru G, Mudge M, Cottrell S. Quality of life impairment, disability and economic burden associated with chronic daily headache, focusing on chronic migraine with or without medication overuse: a systematic review. Cephalalgia. 2011;31:837-50.

7. Aurora SK, Dodick DW, Turkel CC, et al. OnabotulinumtoxinA for treatment of chronic migraine: results from the double-blind, randomized, placebo-controlled phase of the PREEMPT 1 trial. Cephalalgia. 2010;30:793-803.

8. Diener HC, Dodick DW, Aurora SK, et al. OnabotulinumtoxinA for treatment of chronic migraine: results from the double-blind, randomized, placebo-controlled phase of the PREEMPT 2 trial. Cephalalgia. 2010;30:804-14.

9. Dodick DW, Turkel CC, DeGryse RE, et al. OnabotulinumtoxinA for treatment of chronic migraine: pooled results from the double-blind, randomized, placebo-controlled phases of the PREEMPT clinical program. Headache. 2010;50:921-36.

10. Lipton RB, Rosen NL, Ailani J, DeGryse RE, Gillard PJ, Varon SF. OnabotulinumtoxinA improves quality of life and reduces impact of chronic migraine over one year of treatment: pooled results from the PREEMPT randomized clinical trial program. Cephalalgia. 2016;36:899-908. 
11. Tfelt-Hansen P, Block G, Dahlof C, et al. Guidelines for controlled trials of drugs in migraine: second edition. Cephalalgia. 2000;20:765-86.

12. Tassorelli C, Diener HC, Dodick DW, et al. Guidelines of the International Headache Society for controlled trials of preventive treatment of chronic migraine in adults. Cephalalgia. 2018;38:815-32.

13. Dodick DW, Turkel CC, DeGryse RE, et al. Assessing clinically meaningful treatment effects in controlled trials: chronic migraine as an example. J Pain. 2015;16:164-75.

14. Matharu M, Halker R, Pozo-Rosich P, DeGryse R, Manack Adams A, Aurora SK. The impact of onabotulinumtoxinA on severe headache days: PREEMPT 56-week pooled analysis. J Headache Pain. 2017;18:78.

15. Kosinski M, Bayliss MS, Bjorner JB, et al. A six-item short-form survey for measuring headache impact: the HIT-6. Qual Life Res. 2003;12:963-74.

16. Jhingran P, Davis SM, LaVange LM, Miller DW, Helms RW. MSQ: Migraine-Specific Quality-of-Life Questionnaire. Further investigation of the factor structure. Pharmacoeconomics. 1998;13:707-17.

17. Rendas-Baum R, Bloudek LM, Maglinte GA, Varon SF. The psychometric properties of the MigraineSpecific Quality of Life Questionnaire version 2.1 (MSQ) in chronic migraine patients. Qual Life Res. 2013;22:1123-33.

18. Lampl C, Rudolph M, Bräutigam E. OnabotulinumtoxinA in the treatment of refractory chronic cluster headache. J Headache Pain. 2018;19:45.

19. Bendtsen L, Sacco S, Ashina M, et al. Guideline on the use of onabotulinumtoxinA in chronic migraine: a consensus statement from the European Headache Federation. J Headache Pain. 2018;19:91.

20. Tassorelli C, Aguggia M, De Tommaso M, et al. OnabotulinumtoxinA for the management of chronic migraine in current clinical practice: results of a survey of sixty-three Italian headache centers. J Headache Pain. 2017;18:66.

21. Ornello R, Guerzoni S, Baraldi C, et al. Sustained response to onabotulinumtoxinA in patients with chronic migraine: real-life data. J Headache Pain. 2020;21:40.

22. Torres-Ferrus M, Gallardo VJ, Alpuente A, PozoRosich P. Influence of headache pain intensity and frequency on migraine-related disability in chronic migraine patients treated with onabotulinumtoxinA. J Headache Pain. 2020;21:88.

23. Buse DC, Lipton RB, Hallstrom Y, et al. Migrainerelated disability, impact, and health-related quality of life among patients with episodic migraine receiving preventive treatment with erenumab. Cephalalgia. 2018;38:1622-31.

24. Brossner G, Reuter U, Bonner JH, et al. MTIS2018074. Efficacy outcomes in responder and non-responder patients with episodic migraine treated preventively with erenumab in STRIVE [abstract]. Cephalalgia. 2018;38:55-6. 